\title{
Use of combined fermentation technology to improve the efficiency of the energy complex of the MSW landfil
}

\author{
A V Sadchikov* \\ Department of Electrical and Thermal Power Engineering, Orenburg State University, Orenburg, Russia
}

\begin{abstract}
The article analyzes the existing problems associated with the degassing of landfill and the use of landfill gas as an energy resource. Issues related to the composition of the landfill gas are considered. The main reasons for the high nitrogen content in landfill gas are shown. The main measures are highlighted that make it possible to increase the economic attractiveness of the use of landfill gas. A fundamentally new technology of combined fermentation has been proposed, combining the fundamentals of the technologies of "dry" and "wet" fermentation of various substrates. The paper presents the results of using the technology of combined fermentation to increase the efficiency of the active decontamination system of the MSW landfill of WSC Vodino LLC. A significant improvement in the composition of landfill gas was noted, first of all, an increase in the volume fraction of methane and an increase in the average daily volume of recoverable landfill gas by $22 \%$. As a result, the daily production of heat and electricity at the site during the experiment increased by $79.6 \%$. As a side effect in the experiment, a decrease in the height of the horizon of the landfill body was noted by $12.5 \%$ and, as a consequence, an increase in the useful capacity of the landfill.
\end{abstract}

\section{Introduction}

The complex for solving problems associated with the degassing of MSW landfills includes both problems associated with the collection, storage and disposal of landfill gas, as well as problems of landfill reclamation $[1,2]$.

The use of landfill gas in its raw form can be extremely difficult - not only because of the low methane component, but also because of the presence of difficult to separate components, such as nitrogen.

\section{Theoretical analysis}

Currently, information on the composition of landfill gas, cited in many available domestic and foreign sources, is very different in terms of the volume fraction of nitrogen. The most common misconception is the statement that the typical composition of landfill gas corresponds to a volume fraction of $\mathrm{N} 2$ of no more than $2 \div 5 \%$, whereas, unlike biogas of methane tanks, nitrogen may be present in an amount of $20 \%$ or more in landfill gas.

Nitrogen belongs to the non-combustible (ballast) components of the gas mixture, and when the nitrogen content in the gas is more than $8 \%$, it must be separated, and the process of nitrogen separation is rather complicated and energy-consuming, compared to the process of separating other macrocomponents of landfill gas, such as hydrogen sulfide and carbon dioxide.
There may be several reasons for the high nitrogen content, of which two should be highlighted:

- the composition of the substrate and the nature of microbiological processes in the body of the landfill, depending on the characteristics and age of the landfill;

- air leaks into the landfill body and landfill gas collection system during its degassing.

Obviously, in order to increase the efficiency of gasification of landfills, we need to search for new scientific and technical solutions aimed at increasing the methane component of landfill gas and reducing the proportion of ballast components, improving the quality of collecting, storing and utilizing landfill gas, improving environmental safety and energy independence of the landfill.

The problem of using landfill gas for generating electric and thermal energy associated with the component composition of landfill gas can be solved through the implementation of three main areas:

- highly effective microbiological impact on the landfill body to increase the metabolic activity of the local consortium of microorganisms, as well as to reduce the volume fraction of ballast gas impurities and increase the methane component of landfill gas to purification systems;

- creation of a more perfect and effective purification system of the resulting gas mixture;

- improve the efficiency of landfill gas burning devices.

Systems and methods for cleaning landfill gas in modern literature are represented by a large variety [3-

Corresponding author: lyohantron@ mail.ru 
8], but almost all the devices and installations offered today, both domestic and foreign, do not provide for the control and separation of nitrogen.

When analyzing the operation of burners, it was found that the use of landfill gas and biogas is possible with minimal expenditure on purification systems (with mandatory separation of moisture, sulfur, etc.), and there was a slight decrease in plant efficiency. To improve the efficiency of landfill gas and methane tank biogas, technical solutions were proposed, as reflected in [9], as well as in $[10,11]$.

In this regard, the development of the most efficient and low-cost method for increasing the methane component while reducing the nitrogen content in landfill gas is an urgent task, the solution of which will significantly increase the economic attractiveness of using landfill gas as an energy resource.

\section{Proposed technique}

To increase the metabolic activity of the microbiological consortium, as well as to reduce the volume fraction of ballast gas impurities and increase the methane component of the landfill gas, in this paper a method based on the technology of combined fermentation was proposed.

The technology of combined fermentation is a set of technological processes connected in a single bioenergy cycle and combining the fundamentals of technologies of "dry" and "wet" fermentation, i.e. the principles of the fermentation of substrates with a moisture content of less than $50 \%$ and the principles of obtaining methane effluent with anaerobic digestion of substrates with a moisture content of $86 \%$ and higher.

It was previously established that it is possible to increase the methane component in biogas due to various combinations of nutrient substrates, including substrates with rapid splitting [12,13], as well as [14-16].

At the same time, the highest rates of $\mathrm{CH} 4$ (up to $78.5 \%$ of methane in crude biogas) were observed in the case of pretreatment of loading components with methane effluent or preparations based on it. This gave grounds to suggest the possibility of using biopreparations based on methane effluent for treating substrates in the body of the MSW landfill with the aim of increasing methane recovery and environmental safety.

Thus, the basis of the technology of combined fermentation in this case is the use of methane effluent of the bioenergy station as a biogenic amplifier - a stabilizer of the processes of active degassing of MSW sites. The principal novelty of the proposed technical solutions is partly reflected in [17]. Estimation of the expected effect from the application of the method described in [17] is based on the experience of using methane effluent for treating several groups of substrates of different morphological composition and analyzing the composition of the gas mixtures formed. In all cases, an increase in the volume fraction of the methane component was observed already on the 6th to 10th day after the first application.

\section{Results of research and their discussion}

MSW landfill LLC "WSC Vodino" is located near the city of Samara. The landfill of the pit type, with a capacity of 130 million $\mathrm{m} 3$, the annual volume of waste disposed of at the time of the study was 1.1 million $\mathrm{m} 3$. The energy system of active degassing of the landfill of the WSC Vodino LLC at the time of the study included 22 gas wells located on the first process map of the landfill (Fig. 1).

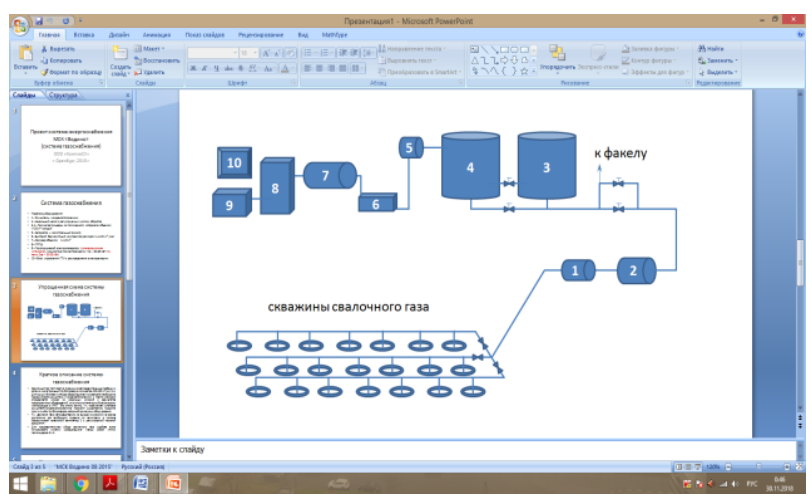

Fig. 1. The energy system of active degassing on the first technological map of the MSW landfill LLC "WSC Vodino" (1 - Dryer - condensate receiver; 2 - Duct pump with adjustable speed; 3,4 - Light gas tanks made of polymeric material; 5 Separator and main filter; 6 - Screw oil-free compressor; 7 Landfill gas receiver; 8 - Gas control point; 9 - Gas piston cogeneration unit; 10 - The control unit and the distribution of energy).

The system of active degassing of the landfill, shown in Fig. 1 includes a unit for generating electrical and thermal energy based on a gas piston unit. Before the start of the experiment, it was planned to generate electrical and heat energy from landfill gas at the MSW landfill site of LLC WSC Vodino on a $35 \mathrm{~kW}$ Capstoun microturbine. However, the turbine commissioning never took place, since According to the research data, the landfill gas of the MSW landfill WSC Vodino LLC comprised $41 \%$ of methane by volume, $23 \%$ of nitrogen (!) and $30 \%$ of carbon dioxide.

Based on the analysis of the existing degassing system, a set of measures was developed aimed at increasing the efficiency of the active degassing of the landfill.

In the project, a methane effluent was proposed as a biogenic amplifier - stabilizer of the processes of active decontamination of the landfill of MSW Vodino LLC in the project. In the experiment, the methane effluent of the Eco-Volt-Agro bioenergy station was used by the company KompleSU, Orenburg.

The essence of the proposed method is as follows. After sampling the substrate body of the landfill at a depth of extraction (at the time of the survey 2.2-2.5 m), methane effluent was introduced into each well in an amount necessary to achieve the required carbon to nitrogen ratio of 23: 1 . The value of $\mathrm{pH} \mathrm{pH}$ was maintained in the range from 7.8 to 8.1 . The frequency of application was determined by the duration of the 
Table 1. Experimental Indicators.

\begin{tabular}{|c|c|c|c|c|c|}
\hline Indicator & \multicolumn{5}{|c|}{ Experiment days } \\
\hline & $\mathbf{0}$ & $\mathbf{6}$ & $\mathbf{1 2}$ & $\mathbf{1 8}$ & $\mathbf{2 4}$ \\
\hline Volume fraction $\mathrm{CH}_{4}, \%$ & 41,0 & 42,5 & 46,2 & 49,4 & 64,0 \\
\hline The heat value of landfill gas, MJ/m ${ }^{3}$ & 20,512 & 21,263 & 23,114 & 24,715 & 32,019 \\
\hline Volume of gas produced $\mathrm{V}_{\mathrm{C \Gamma}}, \mathrm{m}^{3} /$ day & 106,4 & 102,8 & 110,7 & 116,2 & 122,4 \\
\hline Thermal energy $\mathrm{Q}_{\mathrm{HE}}, \mathrm{MJ} /$ day & 916,65 & 918,04 & 1074,65 & 1206,18 & 1646,04 \\
\hline Electric energy $\mathrm{W}_{\mathrm{EE}}, \mathrm{kW} \cdot \mathrm{h} /$ day & 218,25 & 218,58 & 255,87 & 287,18 & 391,92 \\
\hline
\end{tabular}

bioenergy cycle of the combined fermentation. Over the entire period of the experiment ( 24 days), 3 to 4 infusions were made in each well. Every 6 days, sampling of landfill gas, control measurements and calculations of the main indicators were performed, the results of which are shown in Table 1.

The results of the implementation of the proposed technology are quite clearly illustrated by the graph of the dynamics of changes in the composition of the landfill gas of the MSW landfill WSC Vodino, shown in
Fig. 2. Due to the increase in the caloric content of the landfill gas, as well as due to the growth in the volume of recoverable gas, the production of heat and electric energy has increased significantly (Fig. 3, Fig. 4).

The effectiveness of the proposed technology is due not only to the rapid growth in the volume fraction of methane in the landfill gas, but also to a significant improvement in the environmental and economic indicators of the landfill.

The technical result of the use of technology

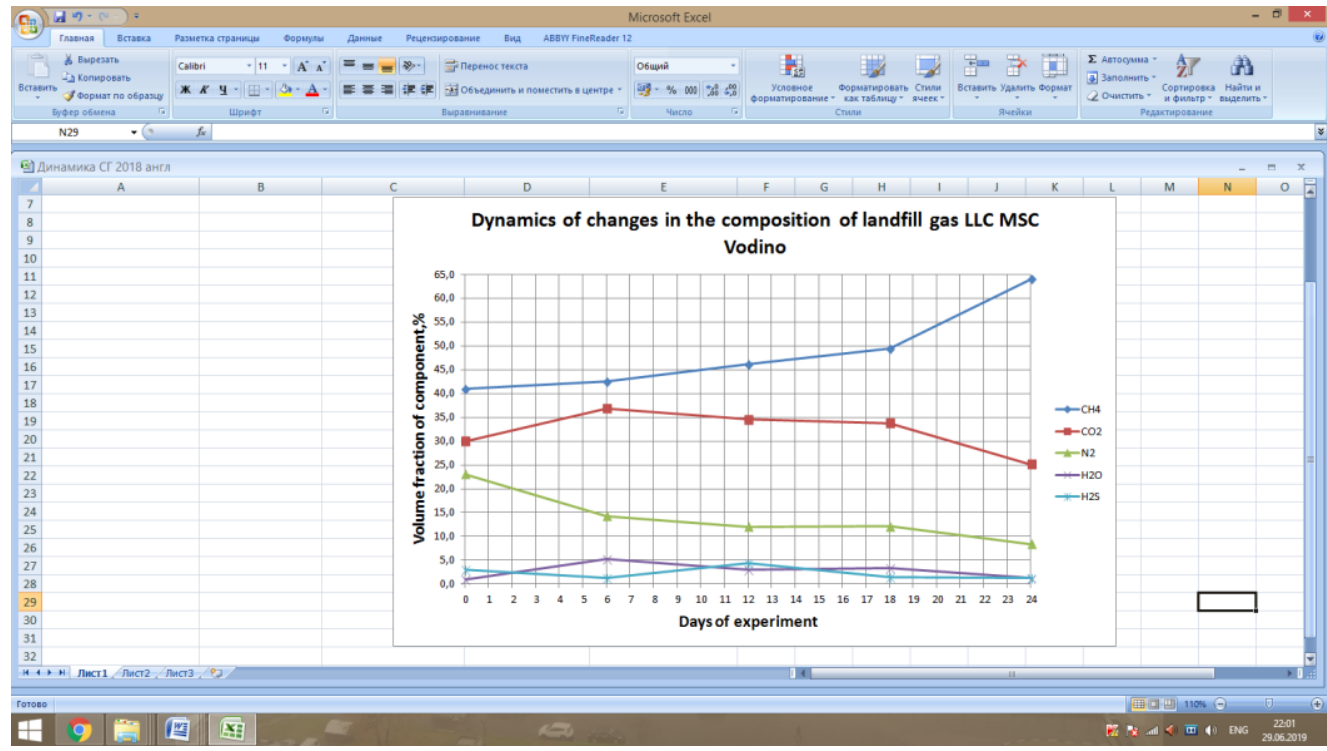

Fig. 2. Indicators of changes in the composition of landfill gas MSW landfill LLC "WSC Vodino".

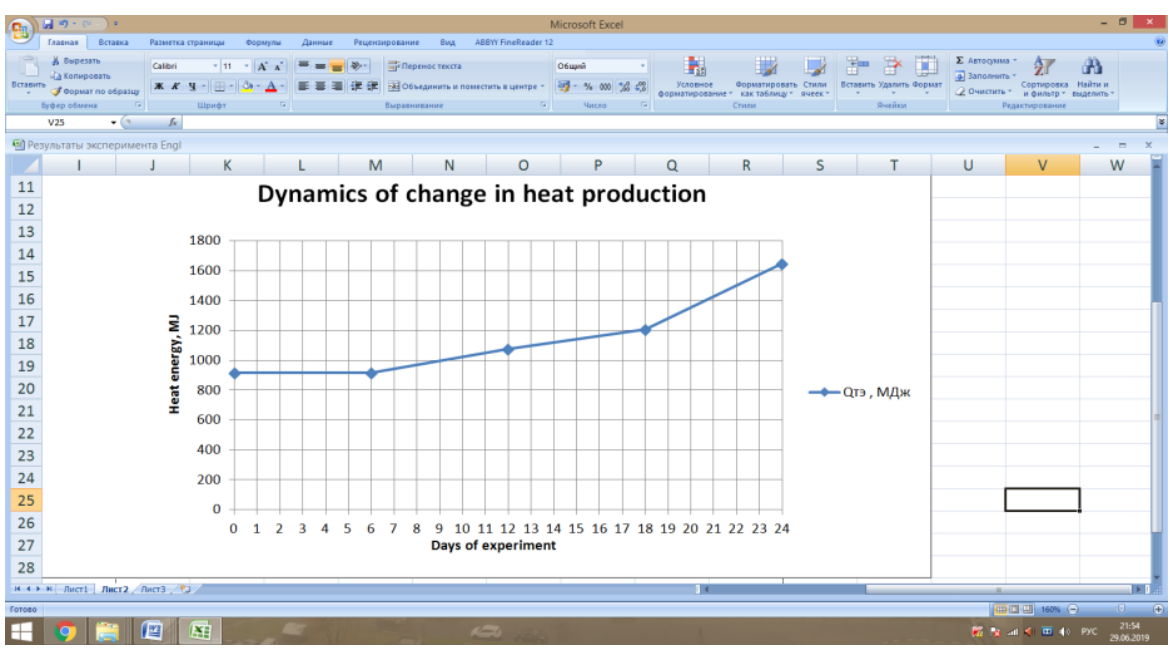

Fig. 3. Dynamics of change in generated heat energy. 


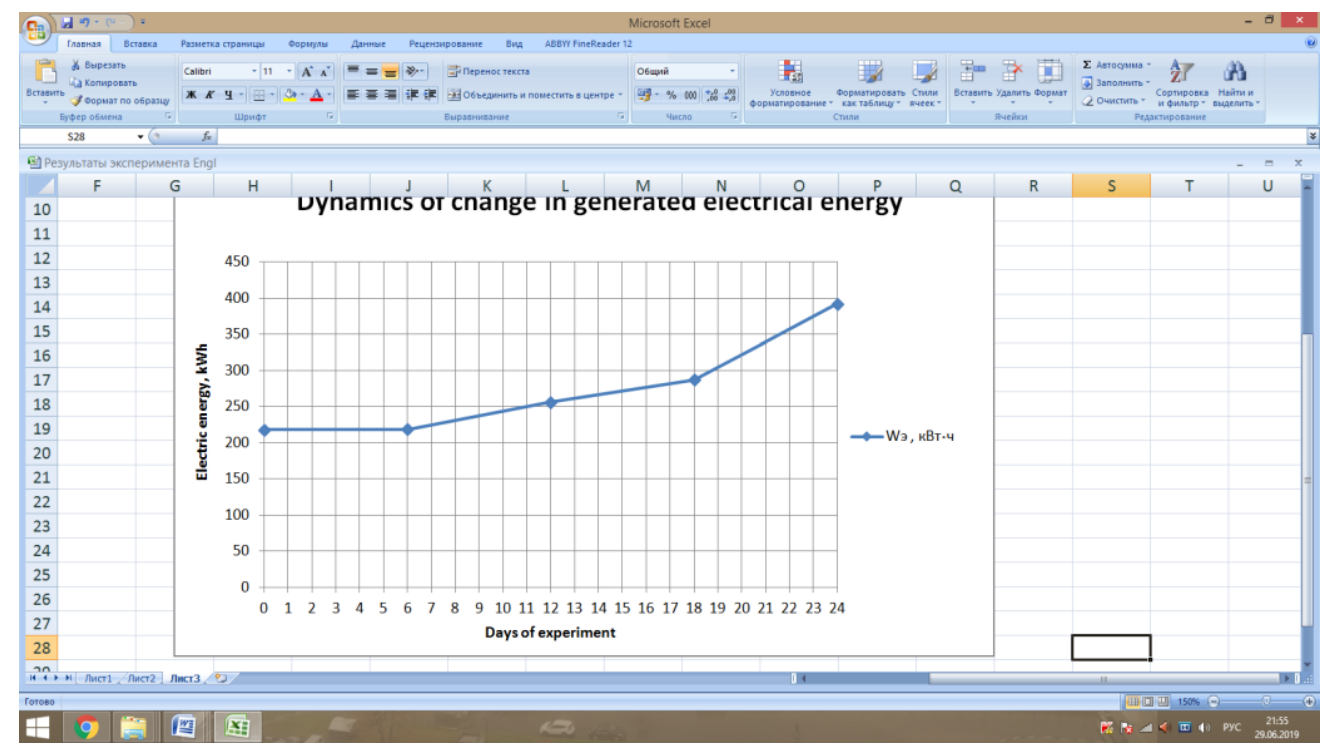

Fig. 4. Dynamics of change in generated electrical energy.

combined fermentation are:

- higher activity of the methanogenic consortium contained in the effluent, in the absence of costs for the cultivation of strains of microorganisms;

- improving the efficiency and speed of recycling, accompanied by a decrease in hazard class from IV (low hazard) to V (non hazardous) [18];

- increase the useful capacity of the landfill;

- reduction of landfill gas emissions into the atmosphere;

- elimination of landfill gas fires;

- ensuring the necessary parameters of landfill gas for its subsequent use in power plants, primarily by the amount of nitrogen and carbon dioxide;

- increase of methane component of landfill gas and its calorific value.

- ensuring the energy independence of the MSW landfill.

\section{Conclusion}

During the course of the experiment, the quality indicators of landfill gas significantly improved, an increase in gas formation intensity and an increase in the average daily volume of recoverable landfill gas by $22 \%$ were noted, the daily energy production at the site increased by $79.6 \%$.

It should be noted that the technology of combined fermentation is effective for landfills of various types, especially for those in which there are no systems for collecting and returning the filtrate. In essence, the proposed technology of combined fermentation combines the basics of the technologies of "dry" and "wet" fermentation, i.e. Principles of substrate fermentation with a moisture content of less than $50 \%$ using methane effluent, obtained by anaerobic digestion of substrates with a moisture content of $86 \%$ or more. As a side effect in the experiment, a decrease in the height of the horizon of the landfill body was noted by $12.5 \%$ and, as a consequence, an increase in the useful capacity of the landfill. The gained experience can be used in the further introduction and development of this technology for the development and rehabilitation of existing and projected MSW landfills

\section{References}

1. Federal Law of December 29, 2014 No. 458-FZ "On Amendments to the Federal Law" On "Production and Consumption Wastes", Certain Legislative Acts of the Russian Federation and Recognition of Certain Legislative Acts (Provisions of Legislative Acts) of the Russian Federation"

2. A.V. Sadchikov, V.Y. Sokolov, N.F. Kokarev, S.A. Naumov, Ensuring energy independence and improvement on the environmental safety of landfill, International Scientific Journal for Alternative Energy and Ecology, 15-18(203-206), 104-11 (2016)

3. A. Mehrotra, A.D. Ebner, J.A. Ritter, Arithmetic approach for complex, PSA cycle scheduling Adsorption, 16(3),113-26 (2010)

4. A. Agarwal, L.T. Biegler, S.E. Zitney, A superstructure-based optimal synthesis of PSA cycles for post-combustion $\mathrm{CO} 2$ effectively captureure, AIChE Journal, 56(7), 1813-28 (2010)

5. A. Mehrotra, A.D. Ebner, J.A. Ritter J A 2011 Simplified graphical approach for complex PSA cycle scheduling, Adsorption, 17(2), 337-45 (2011)

6. B.H.L. Betlem, R.W.M. Gotink, H. Bosch, Optimal operation of rapid pressure swing adsorption with slop recycling, Computers and Chemical Engineering, 22(1), 633-36 (1998)

7. A.V. Sadchikov, V.Y. Sokolov, S.A. Naumov, S.V. Mitrofanov, Use of natural zeolite in systems for separation and purification of gas mixtures containing methane, Key Engineering Materials, 736, 179-82 (2017) 
8. V.V. Bukhmirov, A.V. Sadchikov, N.F. Kokarev, Installation of separation of methane-containing gas mixtures of the bioenergy station "Eco-VoltAgro", IOP Conf. Series: Journal of Physics: Conf. Series, 012058 (2017)

9. V.Y. Sokolov, S.A. Naumov, A.V. Sadchikov, S.V. Mitrofanov, Use of ceramic injection molding technology to increase biogas burners efficiency, Key Engineering Materials, 736, 127-31 (2017)

10. RF patent №2479790 IPC F23D 14/02 (2006.01) F23D 14/62 (2006.01). Gas burner / Sokolov V.Yu., Naumov SA, Sadchikov A., Goryachev S.V., Korobkov A.I., Lavrentyev A.V. // Published: 04/20/2013 Bull. № 11

11. RF patent №2471118 IPC F23D 14/66 (2006.01) F23D 14/02 (2006.01). Gas burner / Sokolov V.Yu., Naumov S.A., Sadchikov A.., Goryachev S.V., Lavrentyev A.V., Korobkov A.I. // Published: 12/27/2012 Bul. № 36

12. A.V. Sadchikov, N.F. Kokarev, B.B. Idigenov B B, Use of substrates with fast splitting to increase the methane recovery of biogas plants with a combined load, Modern problems of science and education, 6 (2014)

13. V.V. Bukhmirov, A.V. Sadchikov, N.F. Kokarev, Increase Methane Emission of Biogas Plant Using Combined Charging Raw Materials, International Ural Conference on Green Energy (UralCon), 15660 (2018)

14. RF patent №2515038 IPC C05F 3/00 (2006.01). The method of preparing bird droppings for anaerobic digestion. / Kokarev N.F., Sadchikov A.V., Nikonorov I.N., Idigenov A.B. // Published: 05/10/2014 Bull. № 13

15. RF Patent No. 2525251 IPC A01C 3/00 (2006.01) C05F 3/00 (2006.01). The method of microbiological processing of bird droppings. / Kokarev N.F., Sadchikov A.V., Idigenov AB, Nikonorov I.N., Idigenov B.B. // Published: 08/10/2014 Bull. № 22

16. RF patent № 2563377 IPC C05F3 / 00 (2006.01). The method of preliminary preparation of bird droppings for subsequent use in the composition of a multicomponent raw materials for singlechamber biogas plant (BGU). / Sadchikov A.V., Idigenov B.B., Kokarev N.F., Nikonorov I.N., Idigenov A.B. // Published 09/20/2015. Bul. № 26

17. RF patent №2555143 IPC B09B1 / 00 (2006.01). The way to improve the efficiency of landfills. /

Sadchikov A.V., Kokarev N.F., Nikonorov I.N., Idigenov A.B. // Posted 07/10/2015. Bul. № 19

18. Federal Waste Classification Catalog: Federal Service for Supervision of Natural Resources Management "ROSPRIRODNADZOR" Access Mode: http://rpn.gov.ru/node/852 